\title{
Smart Home Automation System
}

\author{
Fouad Zaro ${ }^{1}$, Ali Tamimi ${ }^{1}$, and Anas Barakat ${ }^{1}$
}

${ }^{1}$ Affiliation not available

July 9, 2020

\begin{abstract}
This paper presents a low cost, flexible and scalable Smart Home Automation System based on Arduino Technology and Wi-Fi connection, in addition, to apply specific techniques for the reduction of power consumption and load management. The system will be accessible anywhere, anytime for controlling and monitoring. This study relies on Arduino Technology and Node-MCU boards, the electrical appliances are connected to a cloud database that communicates with the user by an android application connected to the internet. A prototype for a specific house has been built, the proposed system is able to control all home electrical units and appliances like lighting, sockets, HVAC units, fire, gas and intruder siren systems, in addition, to monitor the real-time power consumption, the house PV system generation and the current room's temperature and humidity. Furthermore, the system is able to reduce power consumption using predefined algorithms.
\end{abstract}

\section{Hosted file}

Manuscript_Smart-Home-Automation-System.pdf available at https://authorea.com/users/341332/ articles/468270-smart-home-automation-system 